\title{
Solvent-Free Addition of Ethynylbenzene to Ketones
}

\section{Hisakazu Miyamoto,* Shunpei Yasaka, and \\ Koichi Tanaka}

Department of Applied Chemistry, Faculty of Engineering, Ehime University, Matsuyama, Ehime 790-8577

(Received August 28, 2000)

The addition of ethynylbenzene to ketones proceeded efficiently in the absence of a solvent to give tertiary alkynols in good yields.

The alkoxide-catalyzed addition of terminal alkynes to ketones, which proceeds in DMSO, has been known. ${ }^{1}$ Recently, Tzalis et al. reported that $\mathrm{CsOH} \cdot \mathrm{H}_{2} \mathrm{O}$ allowed a catalytic $\mathrm{C}-\mathrm{H}$ activation of various alkynes in solution that leads, in the presence of aliphatic aldehydes or ketones, to propargylic alcohols. ${ }^{2}$ We found that the solvent-free addition of ethynylbenzene to ketones using potassium $t$-butoxide or potassium hydroxide proceed efficiently at room temperature. We now report on an ecologically and economically valuable formation of new carbon-carbon bonds by the solvent-free addition of ethynylbenzene to ketones.

For example, after cyclohexanone 1k (1.0 g, $10.2 \mathrm{mmol})$, ethynylbenzene 2 ( $1.1 \mathrm{~g}, 10.2 \mathrm{mmol}$ ), and potassium $t$-butoxide $(1.1 \mathrm{~g}, 10.2 \mathrm{mmol})$ were well-mixed with agate mortar and pestle, the mixture was kept at room temperature for $20 \mathrm{~min}$. When $1 \mathbf{k}, 2$, and potassium $t$-butoxide were well-mixed in the air, the reaction occurred immediately. After $20 \mathrm{~min}$, the mixture was kept in the crystalline state. Also, the reaction product was mixed with $10 \%$ aqueous sodium chloride to give 1-(phenylethynyl)cyclohexanol (3k $)^{2}$ as colorless crystals $(1.9 \mathrm{~g}, 93 \%$ yield). A similar treatment of dialkyl ketones (1a-e), alkyl phenyl ketones (1f-i), and cyclic ketones (1j and $\mathbf{1 1})$ in the absence of a solvent gave the corresponding tertiary alkynols $\mathbf{3 a}-$ $\mathbf{j}$ and $\mathbf{3 l}$ (Table 1). The addition of ethynylbenzene to 2-cyclohexenone (1m) using potassium $t$-butoxide did not occur either in the absence of a solvent or in solution (Scheme 1, Table 1). The addition of 1-hexyne as another terminal alkynes to cyclo-

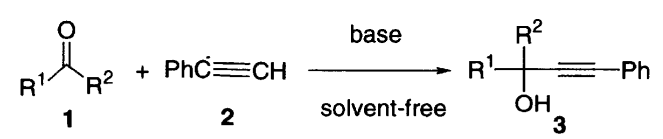

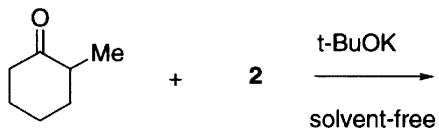

1n

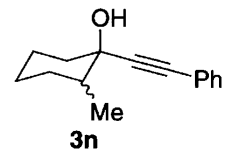

Scheme 1. hexanone $1 \mathbf{k}$ using potassium $t$-butoxide in the absence of a solvent gave the corresponding tertiary alkynol in low yield.

This solvent-free method is much simpler and the yield of the product is higher than that of a solution reaction. For example, a mixture of cyclohexanone $1 \mathbf{k}(1.0 \mathrm{~g}, 10.2 \mathrm{mmol})$, ethynylbenzene 2 (1.0 g, $10.2 \mathrm{mmol})$, and potassium $t$-butoxide $(0.22 \mathrm{~g}, 2.0 \mathrm{mmol})$ was stirred in DMSO $(10 \mathrm{~mL})$ at room temperature for $15 \mathrm{~h}$. Also, the reaction product was mixed with $10 \%$ aqueous sodium chloride to give 1-(phenylethynyl)cyclohexanol $(\mathbf{3 k})^{2}$ as colorless crystals $(1.7 \mathrm{~g}, 83 \%$ yield $)$. We found that these reactions proceed more efficiently in the absence of a solvent than in a DMSO solution (Table 1).

The addition of ethynylbenzene to ketones using potassium hydroxide in solution, which give tertiary alkynols, had been reported by Favorskii. ${ }^{3}$ This reaction is known as the Favorskii reaction. ${ }^{3}$ Tertiary alkynols 3 were also obtained using potassium hydroxide instead of potassium $t$-butoxide. For example, after cyclohexanone $\mathbf{1 k}(1.0 \mathrm{~g}, 10.2 \mathrm{mmol})$, ethynylbenzene $\mathbf{2}$ $(1.1 \mathrm{~g}, 10.2 \mathrm{mmol})$, and potassium hydroxide (1.1 g, 10.2 mmol) were well-mixed with agate mortar and pestle, the mixture was kept at room temperature for $20 \mathrm{~min}$. Also, the reaction product was mixed with $10 \%$ aqueous sodium chloride to give 1-(phenylethynyl)cyclohexanol (3k) as colorless crystals $(1.34 \mathrm{~g}, 66 \%$ yield). The addition of ethynylbenzene to 2-butanone (1b) using potassium hydroxide in the absence of a solvent also gave the corresponding tertiary alkynols $(\mathbf{3 b})$ in $76 \%$

Table 1. Yield of Tertiary Alkynols (3) at Room Temperature in the Absence of a Solvent and Solution ${ }^{\mathrm{a})}$

\begin{tabular}{|c|c|c|c|c|c|}
\hline \multicolumn{3}{|c|}{ Ketone } & \multicolumn{3}{|c|}{ Product and yield $/ \%$} \\
\hline 1 & $\mathrm{R}^{1}$ & $\mathrm{R}^{2}$ & $\begin{array}{c}\text { product } \\
\mathbf{3}\end{array}$ & solvent-free & solution $^{a)}$ \\
\hline$\overline{\mathbf{a}}$ & $\mathrm{Me}$ & $\mathrm{Me}$ & $\mathbf{a}$ & 94 & 91 \\
\hline b & $\mathrm{Me}$ & Et & b & 93 & 78 \\
\hline c & $\mathrm{Me}$ & $\mathrm{nPr}$ & c & 87 & 73 \\
\hline d & Et & Et & d & 83 & 69 \\
\hline $\mathbf{e}$ & iPr & $\mathrm{iPr}$ & $\mathbf{e}$ & 70 & 58 \\
\hline $\mathbf{f}$ & $\mathrm{Ph}$ & $\mathrm{Me}$ & $\mathbf{f}$ & 65 & 43 \\
\hline $\mathbf{g}$ & $\mathrm{Ph}$ & Et & g & 68 & 51 \\
\hline h & $\mathrm{Ph}$ & $\mathrm{nPr}$ & h & 96 & 39 \\
\hline $\mathbf{i}$ & $\mathrm{Ph}$ & $\mathrm{iPr}$ & $\mathbf{i}$ & 72 & 43 \\
\hline $\mathbf{j}$ & & & & 40 & 35 \\
\hline $\mathbf{k}$ & & & & 93 & 83 \\
\hline 1 & & & & 84 & 46 \\
\hline m & & & & b) & b) \\
\hline
\end{tabular}

a) All reaction in solution were carried out in DMSO.

b) No reaction occurred. 
yield.

The solvent-free addition of alkyne to carbonyl compounds with diastereotopic faces, such as 2-methylcyclohexanone (1n), gave a 1:1 mixture of diastereomeric propargyl alcohols $(3 n)^{2}$ in $70 \%$ yield.

Various organic reactions have also been found to proceed efficiently in the solid state. ${ }^{4}$

In summary, we have found that the addition of ethynylbenzene to ketones is very useful and proceeds more efficiently in the absence of a solvent than in a DMSO solution at room temperature.

\section{Experimental}

General Methods. IR spectra were measured with a JASCO FT/IR-350 IR spectrometer, using Nujol mulls. ${ }^{1} \mathrm{H}$ NMR spectra were recorded in $\mathrm{CDCl}_{3}$ on a JEOL JNM-LA300 (300 MHz) spectrometer.

Typical Procedure in the Absence of a Solvent: Preparation of 2-Methyl-4-phenyl-3-butyn-2-ol (3a) ${ }^{5}$ in the Absence of a Solvent. After acetone $1 \mathrm{a}(1.0 \mathrm{~g}, 17.2 \mathrm{mmol})$, ethynylbenzene 2 $(1.8 \mathrm{~g}, 17.2 \mathrm{mmol})$, and potassium $t$-butoxide $(1.9 \mathrm{~g}, 17.2 \mathrm{mmol})$ were well-mixed with agate mortar and pestle, the mixture was kept at room temperature for $20 \mathrm{~min}$. The reaction product was mixed with $10 \%$ aqueous sodium chloride, filtered, washed with water, and dried to give 3a as colorless crystals ( $2.6 \mathrm{~g}, 94 \%$ yield). 3a: $\mathrm{mp} 41-43{ }^{\circ} \mathrm{C}$; IR (Nujol) $3270 \mathrm{~cm}^{-1}$; ${ }^{1} \mathrm{H}$ NMR $\delta 1.64$ (s, 6H), $2.03(\mathrm{~s}, 1 \mathrm{H}), 7.31-7.42(\mathrm{~m}, 5 \mathrm{H})$. Calcd for $\mathrm{C}_{11} \mathrm{H}_{12} \mathrm{O}: \mathrm{C}, 82.46 ; \mathrm{H}$, $7.55 \%$. Found: $\mathrm{C}, 82.59 ; \mathrm{H}, 7.73 \%$. By the same procedure, the following compounds $\mathbf{3 e},{ }^{2} \mathbf{3 f}, \mathbf{3 h}, \mathbf{3 i},{ }^{2} \mathbf{3 k},{ }^{2} \mathbf{3 l}$, and $\mathbf{3} \mathbf{n}^{2}$ as colorless crystals were prepared, in the yields shown in Table 1.3e: mp 39$41{ }^{\circ} \mathrm{C}$; IR (Nujol) $3350 \mathrm{~cm}^{-1}$; ${ }^{1} \mathrm{H}$ NMR $\delta 1.05(\mathrm{~d}, 6 \mathrm{H}), 1.09$ (d, $6 \mathrm{H}), 1.81(\mathrm{~s}, 1 \mathrm{H}), 2.04(\mathrm{~m}, 2 \mathrm{H}), 7.32-7.43(\mathrm{~m}, 5 \mathrm{H})$. Calcd for $\mathrm{C}_{15} \mathrm{H}_{20} \mathrm{O}: \mathrm{C}, 83.28 ; \mathrm{H}, 9.37 \%$. Found: $\mathrm{C}, 83.12 ; \mathrm{H}, 9.37 \%$. 3f: $\mathrm{mp}$ 57-58 ${ }^{\circ} \mathrm{C}$; IR (Nujol) $3300 \mathrm{~cm}^{-1}$; ${ }^{1} \mathrm{H}$ NMR $\delta 1.92$ (s, 3H), 2.42 (s, $1 \mathrm{H}), 7.36-7.74(\mathrm{~m}, 10 \mathrm{H})$. Calcd for $\mathrm{C}_{16} \mathrm{H}_{14} \mathrm{O}: \mathrm{C}, 86.45 ; \mathrm{H}, 6.35 \%$. Found: C, 86.61; H, 6.40\%. 3h: mp 59-61 ${ }^{\circ} \mathrm{C}$; IR (Nujol) 3300 $\mathrm{cm}^{-1}$; ${ }^{1} \mathrm{H}$ NMR $\delta 0.92(\mathrm{~m}, 3 \mathrm{H}), 1.48(\mathrm{~m}, 2 \mathrm{H}), 1.98(\mathrm{~m}, 2 \mathrm{H}), 2.41(\mathrm{~s}$, $1 \mathrm{H})$, 7.34-7.70 (m, 10H). Calcd for $\mathrm{C}_{18} \mathrm{H}_{18} \mathrm{O}: \mathrm{C}, 83.36$; H, 7.25\%. Found: C, 86.21; H, 7.27\%. 3i $\mathbf{i}^{2}$ : mp 54-56 ${ }^{\circ} \mathrm{C}$; IR (Nujol) 3310 $\mathrm{cm}^{-1} ;{ }^{1} \mathrm{H}$ NMR $\delta 0.88(\mathrm{~d}, 3 \mathrm{H}), 1.21(\mathrm{~d}, 3 \mathrm{H}), 2.17(\mathrm{~m}, 1 \mathrm{H}), 2.41(\mathrm{~s}$, 1H), 7.30-7.70 (m, 10H). Calcd for $\mathrm{C}_{18} \mathrm{H}_{18} \mathrm{O}: \mathrm{C}, 86.36 ; \mathrm{H}, 7.25 \%$. Found: C, 86.42; H, 7.32\%. 3k $\mathbf{k}^{2}$ : mp 49-50 ${ }^{\circ} \mathrm{C}$; IR (Nujol) 3220 $\mathrm{cm}^{-1} ;{ }^{1} \mathrm{H}$ NMR $\delta$ 1.27-2.02 (m, 10H), $2.03(\mathrm{~s}, 1 \mathrm{H}), 7.30(\mathrm{t}, 3 \mathrm{H})$, $7.44(\mathrm{~d}, 2 \mathrm{H})$. Calcd for $\mathrm{C}_{14} \mathrm{H}_{16} \mathrm{O}: \mathrm{C}, 83.96 ; \mathrm{H}, 8.05 \%$. Found: $\mathrm{C}$, 84.06; H, 8.20\%. 3I: $\mathrm{mp} \mathrm{38-40}{ }^{\circ} \mathrm{C}$; IR (Nujol) $3270 \mathrm{~cm}^{-1}$; ${ }^{1} \mathrm{H}$ NMR $\delta 1.56-2.15(\mathrm{~m}, 12 \mathrm{H}), 1.96$ (s, 1H), 7.31-7.43 (m, 5H). Calcd for $\mathrm{C}_{15} \mathrm{H}_{18} \mathrm{O}: \mathrm{C}, 84.07 ; \mathrm{H}, 8.47 \%$. Found: C, 84.08; $\mathrm{H}$, 8.62\%. 3n: mp 80-82 ${ }^{\circ} \mathrm{C}$; IR (Nujol) $3370 \mathrm{~cm}^{-1}$; ${ }^{1} \mathrm{H}$ NMR $\delta 1.12$ (d, 3H), 1.22-1.78 (m, 9H), $2.17(\mathrm{~s}, 1 \mathrm{H}), 7.26-7.47$ (m, 5H). Calcd for $\mathrm{C}_{15} \mathrm{H}_{18} \mathrm{O}: \mathrm{C}, 84.07 ; \mathrm{H}, 8.47 \%$. Found: C, 84.07; H, 8.47\%.

Preparation of 3-Methyl-1-phenyl-1-pentyn-3-ol (3b) ${ }^{6}$ in the Absence of a Solvent. After 2-butanone $1 \mathbf{b}(1.0 \mathrm{~g}, 13.9 \mathrm{mmol})$, ethynylbenzene $2(1.4 \mathrm{~g}, 13.9 \mathrm{mmol})$, and potassium $t$-butoxide $(1.6 \mathrm{~g}, 13.9 \mathrm{mmol})$ were well-mixed with agate mortar and pestle, the mixture was kept at room temperature for $20 \mathrm{~min}$. The reaction product was mixed with $10 \%$ aqueous sodium chloride and ex- tracted twice with ether $10 \mathrm{~mL}$. The ether solution was dried over $\mathrm{MgSO}_{4}$, evaporated to give $\mathbf{3 b}$ as colorless oil (2.2 g, $93 \%$ yield). 3b: IR (Neat) $3370 \mathrm{~cm}^{-1}$; ${ }^{1} \mathrm{H}$ NMR $\delta 1.13(\mathrm{~m}, 3 \mathrm{H}), 1.58(\mathrm{~s}, 3 \mathrm{H})$, $1.78(\mathrm{~m}, 2 \mathrm{H}), 2.06(\mathrm{~s}, 1 \mathrm{H}), 7.26-7.48(\mathrm{~m}, 5 \mathrm{H})$. Calcd for $\mathrm{C}_{12} \mathrm{H}_{14} \mathrm{O}$ : $\mathrm{C}, 82.72 ; \mathrm{H}, 8.10 \%$. Found: $\mathrm{C}, 82.72 ; \mathrm{H}, 8.10 \%$. By the same procedure, the following compounds $\mathbf{3 c}, \mathbf{3 d},{ }^{1,6} \mathbf{3 g}$, and $\mathbf{3 j}$ as colorless oil were prepared, in the yields shown in Table 1. 3c: IR (Neat) $3360 \mathrm{~cm}^{-1}$; ${ }^{1} \mathrm{H}$ NMR $\delta 1.02(\mathrm{~m}, 3 \mathrm{H}), 1.56(\mathrm{~s}, 3 \mathrm{H}), 1.63(\mathrm{~m}, 2 \mathrm{H})$, $1.75(\mathrm{~m}, 1 \mathrm{H}), 2.06(\mathrm{~s}, 1 \mathrm{H}), 7.30-7.43(\mathrm{~m}, 5 \mathrm{H})$. Calcd for $\mathrm{C}_{13} \mathrm{H}_{16} \mathrm{O}$ : C, 82.94; H, 8.57\%. Found: C, 82.65; H, 8.67\%. 3d: IR (Neat) $3380 \mathrm{~cm}^{-1}$; ${ }^{1} \mathrm{H}$ NMR $\delta 1.11(\mathrm{~m}, 6 \mathrm{H}), 1.76(\mathrm{~m}, 4 \mathrm{H}), 1.99(\mathrm{~s}, 1 \mathrm{H})$, 7.31-7.42 (m, 5H). Calcd for $\mathrm{C}_{13} \mathrm{H}_{16} \mathrm{O}: \mathrm{C}, 82.94 ; \mathrm{H}, 8.57 \%$. Found: C, 82.54; H, 8.72\%. 3g: IR (Neat) $3380 \mathrm{~cm}^{-1} ;{ }^{1} \mathrm{H}$ NMR $\delta$ $1.01(\mathrm{~m}, 3 \mathrm{H}), 2.08(\mathrm{~m}, 2 \mathrm{H}), 2.59(\mathrm{~s}, 1 \mathrm{H}), 7.28-7.69(\mathrm{~m}, 10 \mathrm{H}) . \mathrm{Cal}-$ cd for $\mathrm{C}_{17} \mathrm{H}_{16} \mathrm{O}: \mathrm{C}, 86.40 ; \mathrm{H}, 6.82 \%$. Found: $\mathrm{C}, 86.08 ; \mathrm{H}, 6.82 \%$. 3j: IR (Neat) $3350 \mathrm{~cm}^{-1} ;{ }^{1} \mathrm{H}$ NMR $\delta 1.75-2.08(\mathrm{~m}, 8 \mathrm{H}), 1.87$ (s, $1 \mathrm{H}), 7.30-7.12(\mathrm{~m}, 5 \mathrm{H})$. Calcd for $\mathrm{C}_{13} \mathrm{H}_{14} \mathrm{O}: \mathrm{C}, 83.83 ; \mathrm{H}, 7.58 \%$. Found: C, 83.39; H, 7.70\%.

Preparation of 1-(Phenylethynyl)cyclohexanol $(3 k)^{2}$ in the Absence of a Solvent. Using potassium hydroxide as a base, after cyclohexanone $1 \mathrm{k}(1.0 \mathrm{~g}, 10.2 \mathrm{mmol})$, ethynylbenzene 2 (1.0 $\mathrm{g}, 10.2 \mathrm{mmol})$, and potassium hydroxide $(1.1 \mathrm{~g}, 10.2 \mathrm{mmol})$ were well-mixed with agate mortar and pestle, the mixture was kept at room temperature for $20 \mathrm{~min}$. The reaction product was mixed with $10 \%$ aqueous sodium chloride, filtered, washed with water, and dried to give 1-(phenylethynyl)cyclohexanol (3k) as colorless crystals (1.34 g, 66\% yield).

Typical procedure in DMSO: Preparation of 1-(Phenylethynyl)cyclohexanol (3k) in DMSO. A mixture of cyclohexanone $1 \mathbf{k}(1.0 \mathrm{~g}, 10.2 \mathrm{mmol})$, ethynylbenzene $2(1.0 \mathrm{~g}, 10.2 \mathrm{mmol})$, and potassium $t$-butoxide $(0.22 \mathrm{~g}, 2.0 \mathrm{mmol})$ was stirred in DMSO 10 $\mathrm{mL}$ at room temperature for $15 \mathrm{~h}$. The reaction product was mixed with $10 \%$ aqueous sodium chloride, filtered, and washed with water, and dried to give 1-(phenylethynyl)cyclohexanol (3k) as colorless crystals ( $1.7 \mathrm{~g}, 83 \%$ yield).

This work was supported by a Grant-in-Aid for Scientific Research from the Ministry of Education, Science and Culture, Japanese Government, and by Mitsubishi Chemical Corporation Fund (to H.M.). Elemental analyses were performed at the Advanced Instrumentation Center for Chemical Analysis, Ehime University. Technical assistance from Taku Kimura is gratefully acknowledged.

\section{References}

1 J. H. Babler, V. P. Liptak, and N. Phan, J. Org. Chem., 61, 416 (1996).

2 D. Tzalis and P. Knochel, Angew. Chem., Int. Ed.Engl., 37, 1463 (1999).

3 A. E. Favorskii, Bull. Soc. Chim. Fr., 2, 1087 (1907); A. E. Favorskii, J.Russ. Phys.-Chem.Ges., 37, 643 (1905).

4 F. Toda, Acc. Chem. Res., 28, 480 (1995); K. Tanaka and F. Toda, Chem. Rev., 100, 1025 (2000).

5 F. J. Wilson and W. M. Hyslop, J. Chem. Soc., 1923, 2612.

6 A. I. Kosak, R. J. F. Palchak, W. A. Steele, and C. M. Selwitz, J. Am. Chem. Soc., 76, 4446 (1954). 